\title{
Anticancer Activities of Ginsenosides, the Main Active Components of Ginseng
}

\author{
Heeok Hong $\mathbb{D}^{1}{ }^{1}$ Delgerzul Baatar $\mathbb{D}^{2},{ }^{2}$ and Seong Gu Hwang $\mathbb{D}^{3}$ \\ ${ }^{1}$ Department of Animal Science and Technology, Konkuk University, Seoul 05029, Republic of Korea \\ ${ }^{2}$ Laboratory of Genetics, Institute of Biology, Mongolian Academy of Sciences, Peace Avenue 13330, Ulaanbaatar, Mongolia \\ ${ }^{3}$ Department of Animal Life and Environmental Science, Hankyong National University, Anseong City 17579, Republic of Korea
}

Correspondence should be addressed to Seong Gu Hwang; sghwang@hknu.ac.kr

Received 20 August 2020; Revised 20 January 2021; Accepted 27 January 2021; Published 3 February 2021

Academic Editor: Takuhiro Uto

Copyright (@) 2021 Heeok Hong et al. This is an open access article distributed under the Creative Commons Attribution License, which permits unrestricted use, distribution, and reproduction in any medium, provided the original work is properly cited.

Cancer incidence rate has been increasing drastically in recent years. One of the many cancer treatment methods is chemotherapy. Traditional medicine, in the form of complementary and alternative therapy, is actively used to treat cancer, and many herbs and active ingredients of such therapies are being intensely studied to integrate them into modern medicine. Ginseng is traditionally used as a nourishing tonic and for treating various diseases in Asian countries. The therapeutic potential of ginseng in modern medicine has been studied extensively; the main bioactive component of ginseng is ginsenosides, which have gathered attention, particularly for their prospects in the treatment of fatal diseases such as cancer. Ginsenosides displayed their anticancer and antimetastatic properties not only via restricting cancer cell proliferation, viability, invasion, and migration but also by promoting apoptosis, cell cycle arrest, and autophagy in several cancers, such as breast, brain, liver, gastric, and lung cancer. Additionally, ginsenosides can work synergistically with already existing cancer therapies. Thus, ginsenosides may be used alone or in combination with other pharmaceutical agents in new therapeutic strategies for cancer. To date however, there is little systematic summary available for the anticancer effects and therapeutic potential of ginsenosides. Therefore, we have reviewed and discussed all available literature in order to facilitate further research of ginsenosides in this manuscript.

\section{Introduction}

Today, a growing number of people worldwide have cancer, regardless of wealth or social status. According to a WHO report, 18.1 million people worldwide had cancer in $2018,9.6$ million people died of the disease, and these figures are expected to double by 2040 [1].

At present, the clinical management of cancer always involves several conventional modalities, including surgical resection, radiotherapy, immunotherapy, biotherapy, and chemotherapy [2]. Chemotherapy is currently the most commonly used treatment for cancer [3]. Given that it is difficult to determine an appropriate dosage of conventional chemotherapeutic agents, side effects, such as a reduction in bone density and immunosuppression, often result from high doses, while low levels may not produce desired effects [2]. In addition, some chemotherapeutics may cause acquired drug resistance. Thus, as the importance of developing a new agent capable of selectively inducing cancer cell death without threatening normal cells emerges, interest in natural products has been amplified.

Over the last few decades, after the introduction of Western medicine into Eastern countries, traditional medicine has been used in the form of complementary and alternative medicine. Herbs and ingredients of traditional medicine are the focus of active research that aims to incorporate them into standard medical treatments.

Ginseng, Panax ginseng C.A. Meyer, has been widely used as a natural tonic in Asian countries, including Korea and China, since ancient times [4]. Among its several active ingredients, ginseng saponins (ginsenosides) are known as the main bioactive agents with various pharmacological activities [5-7]. Many studies have consistently reported that ginsenosides have anticancer effects in several cancer models, even though the exact anticancer mechanism has not been elucidated [8-11]. Therefore, in this review, we 
summarize and discuss the potential roles of ginsenosides in several cancers.

\section{Ethnopharmacological Relevance}

Ginseng is a plant belonging to the Panax genus in the family Araliaceae, and its official scientific name is Panax ginseng [12]. The roots of this plant have been used most frequently for traditional therapeutic purposes for the healing and prevention of human diseases [4]. The oldest document that recorded the usage of ginseng, mainly as a tonic to nourish the vitality of a weak body and as supplementary ingredient for other prescriptions, was written around 2000 years ago $[13,14]$. Indeed, ginseng's genus name Panax means "cure all” in Greek, indicating its potential for treating any illness in traditional medicine $[15,16]$.

Hence, the pharmacological properties of ginseng have been verified by modern science, and its confirmed medicinal effects include immune response boosting [17], anti-inflammatory [18], hepatoprotective [19], antiobesity [20], antimicrobial [21], cognition enhancement [22], and antioxidant effects [6]. Due to its effectiveness for various health situations, ginseng is a popular choice for health products, dietary supplements, and food and cosmetic products [14]. Also, the root of ginseng is currently used for treating cardiovascular diseases [7], autoimmune diseases [23], Alzheimer's disease [24], stress-induced diseases [25], ocular disease [26], and diabetes [5]. Particularly, many studies have suggested that ginsenosides, the saponin components in ginseng, could suppress proliferation, invasion, and inflammation in several cancer cell lines [10, 27-29]. Correspondingly, several clinical studies have reported that ginseng administration could augment the efficacy of therapeutic drugs in patients with cancer $[30,31]$. Oh et al. observed that ginsenosides decreased the viability of breast cancer cells [29], and Kim et al. reported that these compounds blocked the invasion and migration of colon cancer cells [28]. Moreover, Kim et al. [30] and Kim et al. [31] reported that ginseng reduced cancer-related fatigue in colorectal cancer patients with chemotherapy. It is known that cancer-related fatigue severely worsens prognostic outcomes and limits therapeutic options [32]. These results suggest that ginseng has anticancer effects against several cancers and can alleviate the serious side effects associated with cancer treatment.

\section{Components of Ginseng}

Chemical composition of ginseng can be mainly divided into two main types: saponin and non-saponin. Most ginseng components are non-saponin and include carbohydrates, nitrogen-containing compounds, fat soluble components, minerals, and vitamins $[33,34]$. Carbohydrates in ginseng include polysaccharides, oligosaccharides, sugar, fiber, and pectin, with the largest and active carbohydrates being polysaccharides, comprising $50-60 \%$ of ginseng components $[33,35]$. The next major components in ginseng are nitrogen-containing compounds-protein, peptides, amino acids, nucleic acids, and alkaloids [36], while fat soluble components consist of fatty acids, essential oils, phytosterol, organic acids, phenolics, and polyacetylenes [37]. However, saponins are the most studied bioactive components of ginseng. Saponins, mostly known as ginsenosides, are derived from 2,3-oxidosqualene. Depending on the enzyme involved, different types of ginsenoside precursors are produced, dammarenediol-II and $\beta$-amyrin, which are later transformed into tetracyclic dammarane-type and pentacyclic oleanane-type saponins, respectively [38]. Further, dammarane-type saponins are of two different categories, depending on the position of the hydroxyl groups and double bond of their genins [39]. More than 100 ginsenosides have been documented, including 66 protopanaxadiol (PPD), 50 protopanaxatriol (PPT), and 19 oleanane-type ginsenosides [40]. The chemical structures and classifications of ginsenosides are shown in Figure 1.

The diversity of ginsenosides is related to their stereoisomers and constitutional isomers. Some ginsenosides, such as $\mathrm{Rg} 2, \mathrm{Rg} 3, \mathrm{Rh} 1$, and Rh2, exist in different stereoisomeric forms, 20-(S) and 20-(R), depending on the position of the hydroxyl group in C-20. Other ginsenosides, including Rb2, Rb3, Rc, aglycone, Rg1, and F11, contain different saccharide substituents [41, 42]. However, not all ginsenosides occur naturally in ginseng. Several factors influence the ginsenoside components of ginseng: cultivation method, harvesting age, and preparation treatment [43-45].

In general, wild ginseng is believed to have better pharmacological effects compared to the cultivated one. However, due to increasing demand and excessive gathering of wild ginseng, wild simulated ginseng grown in forests and ginseng cultivated in fields are now mostly used. Forest-grown wild simulated ginseng has more Rb1 and Re content than field cultivated ginseng [46]. Another important factor is the timing of the harvest. Ginsenosides are mostly accumulated in the leaves in young plants (1-2 years old) and amassed in roots in later ages (around 5 years); thus, cultivated ginsengs are mostly harvested around 4-6 years old [47]. Moreover, ginseng harvested in the spring has the most total saponin contents than those of other seasons, and Re contents are higher in late spring and lower in the fall than Rg1 contents $[48,49]$. Harvested ginseng can be consumed in their fresh state or after drying. Dried ginseng is commonly referred to as white ginseng, while red ginseng is prepared by steaming the fresh root of ginseng. Steaming changes the chemical composition of ginseng, such that white and red ginseng contain different amounts or varieties of ginsenosides [4]. Naturally occurring ginsenosides can be extracted from harvested fresh ginseng, but most ginsenosides are converted from their original forms by physical, chemical, or biotransformation methods [44]. For instance, major ginsenosides (Rb1, Rb2, Rc, $\mathrm{Rd}, \mathrm{Re}$, and $\mathrm{Rg} 1)$ can be deglycosylated into minor ginsenosides (F2, Rh2, Rg2, Rg3, and CK) [50]. Genetics also plays a role in ginsenoside content, as Korean ginseng ( $P$. ginseng) has more major ginsenosides than the Chinese (P. notoginseng) or American (P. quinquefolius) species [45].

Ginsenosides, important bioactive components in ginseng, have various pharmaceutical activities; however, we will discuss their recently discovered anticancer effects in this review. 


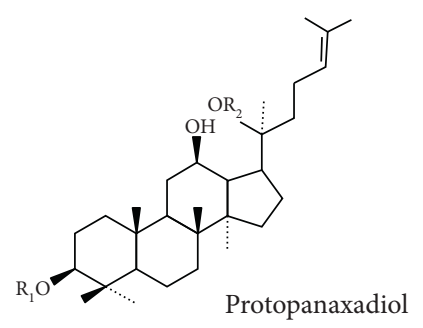

\begin{tabular}{lccc}
\hline Name & $\mathrm{R}_{1}$ & $\mathrm{R}_{2}$ & Formula \\
\hline $\mathrm{Rb}_{1}$ & $\mathrm{glc}^{2} \rightarrow \mathrm{glc}^{1}$ & $\mathrm{glc}^{6} \rightarrow \mathrm{glc}^{1}$ & $\mathrm{C}_{54} \mathrm{H}_{92} \mathrm{O}_{23}$ \\
$\mathrm{Rb}_{2}$ & $\mathrm{glc}^{2} \rightarrow \mathrm{glc}^{1}$ & $\mathrm{glc}^{6} \rightarrow \mathrm{arap}^{1}$ & $\mathrm{C}_{53} \mathrm{H}_{90} \mathrm{O}_{22}$ \\
$\mathrm{Rb}_{3}$ & $\mathrm{glc}^{2} \rightarrow \mathrm{glc}^{1}$ & $\mathrm{glc}^{6} \rightarrow \mathrm{xyl}^{1}$ & $\mathrm{C}_{53} \mathrm{H}_{90} \mathrm{O}_{22}$ \\
$\mathrm{Rc}$ & $\mathrm{glc}^{2} \rightarrow \mathrm{glc}^{1}$ & $\mathrm{glc}^{6} \rightarrow \mathrm{araf}^{1}$ & $\mathrm{C}_{53} \mathrm{H}_{90} \mathrm{O}_{22}$ \\
$\mathrm{Rd}$ & $\mathrm{glc}^{2} \rightarrow \mathrm{glc}^{1}$ & glc & $\mathrm{C}_{48} \mathrm{H}_{82} \mathrm{O}_{18}$ \\
$20-(\mathrm{S}) \mathrm{Rg}_{3}$ & $\mathrm{glc}^{2} \rightarrow \mathrm{glc}^{1}$ & $\mathrm{H}$ & $\mathrm{C}_{42} \mathrm{H}_{72} \mathrm{O}_{13}$ \\
$20-(\mathrm{S}) \mathrm{Rh}_{2}$ & glc & $\mathrm{H}$ & $\mathrm{C}_{36} \mathrm{H}_{62} \mathrm{O}_{8}$ \\
$\mathrm{~F}_{2}$ & $\mathrm{glc}$ & glc & $\mathrm{C}_{42} \mathrm{H}_{72} \mathrm{O}_{13}$ \\
\hline
\end{tabular}

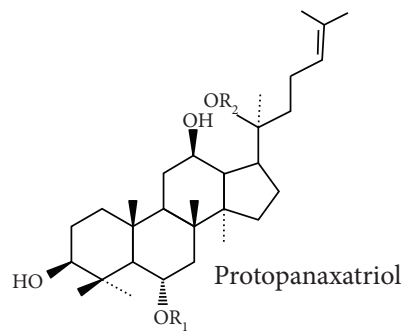

\begin{tabular}{lccc}
\hline Name & $\mathrm{R}_{1}$ & $\mathrm{R}_{2}$ & Formula \\
\hline $\mathrm{Rg}_{1}$ & glc & glc & $\mathrm{C}_{42} \mathrm{H}_{72} \mathrm{O}_{14}$ \\
$20-(\mathrm{S}) \mathrm{Rg}_{2}$ & glc $^{2} \rightarrow \mathrm{rha}^{1}$ & $\mathrm{H}$ & $\mathrm{C}_{42} \mathrm{H}_{72} \mathrm{O}_{13}$ \\
$20-(\mathrm{S}) \mathrm{Rh}_{1}$ & glc & $\mathrm{H}$ & $\mathrm{C}_{36} \mathrm{H}_{62} \mathrm{O}_{9}$ \\
$\mathrm{Re}$ & glc $^{2} \rightarrow \mathrm{rha}^{1}$ & glc & $\mathrm{C}_{48} \mathrm{H}_{82} \mathrm{O}_{18}$ \\
$\mathrm{Rf}$ & glc $^{2} \rightarrow$ glc $^{1}$ & $\mathrm{H}$ & $\mathrm{C}_{42} \mathrm{H}_{72} \mathrm{O}_{14}$ \\
$\mathrm{~F}_{3}$ & $\mathrm{H}$ & glc $^{2} \rightarrow$ arap $^{1}$ & $\mathrm{C}_{47} \mathrm{H}_{70} \mathrm{O}_{13}$ \\
\hline
\end{tabular}

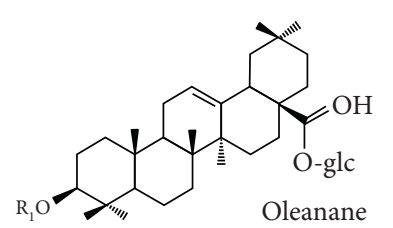

\begin{tabular}{lcc}
\hline Name & $\mathrm{R}_{1}$ & Formula \\
\hline Ro & glcA $^{2}$-glc & $\mathrm{C}_{48} \mathrm{H}_{76} \mathrm{O}_{19}$ \\
\hline
\end{tabular}

FIGUre 1: The chemical structure and classification of ginsenosides. Aaraf: $\alpha$-L-arabinofuranosyl; Arap: $\alpha$-L-arabinopyranosyl; Glc: $\beta$-Dglucopyranaosyl; Rha: $\alpha$-L-rhamnopyranosyl; Xyl: $\beta$-D-xylopyranosyl.

\section{Breast Cancer}

Breast cancer is the most common cancer among women and has a high mortality rate when detected at the late stage. However, breast cancer detected early has a lower mortality rate compared to the incidence rate due to the high probability of cure $[51,52]$. One of the most studied ginsenosides, Rg3, suppressed breast cancer via several intertwined biological pathways related to cell division and protein synthesis, such as by inhibiting Akt-mediated self-renewal signaling in MCF-7 breast cancer cells [29, 53]. Additionally, Rg3 can inhibit the growth of breast cancer cells by downregulating NOX4 and upregulating KDM5A via altering epigenetic methylation [54]. Similarly, Rh2-modulated epigenetic methylation of immune response-related genes can hinder cancer cells growth [55]. Rd also suppressed metastasis by downregulating miR-18a-mediated $\mathrm{Smad} 2$ expression and inhibiting angiogenesis-related vascular endothelial growth factor- (VEGF-) induced Akt activation in cultured or mice xenograft model of MDA MB-231 and 4T1 cells $[56,57]$. Similar to the blocking of breast cancer metastasis by halting Akt-activated cell proliferation by $\mathrm{Rg} 3$ and $\mathrm{Rd}, \mathrm{CK}$ ginsenoside repressed Akt1 signaling to promote apoptosis in SKBR3 cells [29, 57, 58]. Moreover, $\mathrm{CK}, \mathrm{Rg} 5$, and Rk1 suppressed tumor growth in mice xenograft models by inhibiting cyclin D1, phosphatidylinositol-3-kinase (PI3K)/Akt, and reactive oxygen species (ROS)/PI3K/Akt signaling pathway, respectively [59-61]. The activation of the PI3K/Akt pathway, a key regulator of survival, results in the inference of the control of cell growth and survival, ultimately leading to metastatic competence, angiogenesis, and therapy resistance [62].

Furthermore, $\operatorname{Rg} 2$, $\operatorname{Rg} 5$, and CK ginsenoside derivatives induced autophagy, apoptosis, and cell cycle arrest by regulating p53 expression in MCF-7 breast cancer cells [63-65]. Rh2 combined with PPT had a synergistic effect in delaying cell proliferation in the breast cancer cell line MDA-MB-231 [66]. Interestingly, stereoisomerism also plays a role in the potency of ginsenosides; for example, of the two isomers of $\mathrm{Rg} 3,20-(\mathrm{R})$ was more effective in obstructing metastasis (migration and invasion) in MDAMB-231 breast cancer cells [67]. Taken together, ginsenosides exhibit their anticancer effects by inhibiting differentiation, proliferation, and metastasis and induce autophagy, apoptosis, and cell cycle arrest by altering pathways related to carcinogenesis in breast cancer cell lines.

\section{Brain Cancer}

Brain cancer is a tumor located in the brain or central nervous system. The incidence rate of primary brain cancer is relatively low; however, patients with Parkinson's disease have a higher risk of the disease $[68,69]$. About two-thirds of all brain cancers in adults are glioblastoma, the most malignant type of brain cancer with a high mortality rate, in which patients die within 1-2 years of diagnosis [70]. Poorer prognosis of glioblastoma is correlated with the activation of various signaling pathways including the $\mathrm{Wnt} / \beta$-catenin 
signaling pathway $[32,71]$. The binding of the Wnt ligand to the Frizzled receptor stabilizes the transcriptional regulator $\beta$-catenin, which translocates from the cytosol to the nucleus, where it binds to the transcription factor T-cell factor/ lymphoid enhancer-binding factor (TCF/LEF) to promote the expression of its downstream genes, such as TCF1, LEF1, cMYC, and CCND1 [32]. Recent studies have shown that $\mathrm{Rh} 2$ and $\mathrm{Rg} 3$ inhibited migration, proliferation, invasion, and cancer-related inflammation via downregulating Wnt/ $\beta$-catenin signaling in glioblastoma $[32,72]$.

Rg3 also improved the efficiency of temozolomide, a drug for treating glioblastoma, in temozolomide-resistant glioblastoma [73, 74]. Additionally, Rg3, Rb1, and F1 ameliorated senescence, which is one of the side effects of chemotherapy treatment in glioblastoma, and had neuroprotective properties against brain-related diseases [75-77]. $\mathrm{Rh} 2$ reduced proliferation, apoptosis, and metastasis via downregulating miR-31 to suppress $\mathrm{Wnt} / \beta$-catenin signaling and Akt activities, thereby blocking the activation of matrix metalloproteinase (MMP)13, a major degradation enzyme in Daoy medulloblastoma and glioblastoma cells $[72,78]$. Similarly, CK induced cell arrest and apoptosis by repressing the $\mathrm{PI} 3 \mathrm{~K} / \mathrm{Akt} / \mathrm{mTOR}$ pathway in glioblastoma cell lines, U87MG and U373MG [79]. Therefore, ginsenosides inhibit proliferation and induce apoptosis, possibly by blocking signaling pathways related to the deterioration of glioblastoma.

\section{Liver Cancer}

Hepatocellular carcinoma (HCC) is the most common primary liver cancer; it accounts for $80 \%$ of the total cases and is one of the leading causes of cancer-related deaths [80]. Primary risk factors of liver cancer are cirrhosis, hepatitis viral infection, and alcohol consumption [80, 81]. PPD reduced viability and induced apoptosis in HepG2 cells by suppressing the PI3K/Akt pathway [82]. One of the PPDs Rg3 showed antimetastatic effects by upregulating Rho GTPase activating protein 9 (ARHGAP9) and downregulating NHE1 expression in vivo and in vitro $[83,84]$. The overexpression of ARHGAP9, a member of the RhoGAP family, inhibited HCC cell proliferation, migration, invasion, and metastases [85]. Moreover, Rh2 ginsenoside inhibited HCC cell proliferation and growth by modulating $\beta$-catenin signaling and epidermal growth factor receptor (EGFR) signaling. Also, the potency of Rh2 ginsenosides can be increased by upregulating the expression of miR-491 and miR-146a-5p, which play important roles in the development and progress of HCC [86-88]. Compared to the isomer 20-(R), 20-(S) Rh2 reduced cancer cell growth by inactivating Annexin A2; however, there were no differences in effectiveness between the stereoisomers, given that both isomers induced cell apoptosis by downregulating $\mathrm{Bcl}-2$ mRNA in a mouse model of hepatoma [89, 90]. Interestingly, Rg1 not only sensitized hepatoblastoma to DNAdamaging agents but also protected D-gal-induced liver injury in mice by reducing oxidative stress and DNA damage [91, 92]. CK can induce apoptosis by inhibiting the phosphorylated signal transducer and activator of transcription
(STAT) 3 in human HCC xenografted mice models [93]. However, its synthetic mono-octyl ester form had a greater inhibitory effect in murine hepatic carcinoma cell line (H22)-bearing mice than CK [94].

Ginsenosides also enhanced the efficiency of existing drugs for treating liver cancer. For instance, Rg3 combined with sorafenib or oxaliplatin had synergetic effects on inhibiting proliferation, promoting apoptosis, and decreasing tumor volume via regulating the PTEN/Akt signaling pathway or proliferation cell nuclear antigen (PCNA)/cyclin D1 expression, which are key regulators of many cellular processes $[95,96]$. Moreover, $\mathrm{Rh} 2$ combined with regorafenib suppressed HCC cell growth by upregulating caspase- 3 expression and modulating the survivin gene, a member of the apoptosis-inhibiting gene family [97]. Rg3 alleviated transcatheter arterial chemoembolization syndromes and increased survivability in patients with advanced hepatocellular carcinoma [98]. Altogether, ginsenosides reduce cell viability, inhibit tumor growth, and promote apoptosis in HCC independently or in combination with existing drugs.

\section{Gastric Cancer}

Gastric cancer is globally ranked third among the causes of cancer-related death, and the majority of cases are discovered at the late stage, with almost half of the recorded cases from East Asian countries, such as China, Japan, and South Korea $[99,100]$. A report showed that PPD including 25-hydroxyprotopanaxadiol (25-OH-PPD) and 25methoxylprotopanaxadiol (25-OCH3-PPD) had potent anti-tumor properties, such as cell growth inhibition and apoptosis induction in gastric cancer cells lines [101]. Furthermore, 2-Pyrazine-PPD and 4-XL-PPD, the derivatives of 25-OH-PPD, induced apoptosis by producing ROS $[102,103]$. Several studies reported that Rg3 ginsenoside repressed the metastasis of gastric cancer by inhibiting hypoxia-induced factor- $1 \alpha$ (HIF- $1 \alpha$ ) and VEGF expression [104, 105]. In addition, Rg3 had a preventive effect against the risk factors of gastric cancer, gastric precancerous lesions, and Helicobacter pylori [106, 107]. Rg 5 blocked cell growth by inducing G2/M phase cell cycle arrest, apoptosis, and autophagy in xenografted models [108]. Also, Rh2 and Rd induced G0/G1 phase cell cycle arrest and apoptosis by regulating the $\mathrm{Bax} / \mathrm{Bcl}-2$ ratio, which are key proteins associated with apoptosis $[109,110]$. In summary, ginsenosides not only restrict cell viability but also induce apoptosis, cell cycle arrest, and autophagy in gastric cancer cell lines and mice models via regulating the expression of several genes.

\section{Lung Cancer}

Lung cancer, which can be divided into two classes, smallcell and non-small-cell lung carcinomas (NSCLC), is mostly caused by smoking and is the leading cause of cancer-associated mortality worldwide [111]. The most diagnosed lung cancer is NSCLC, which accounts for about $85 \%$ of lung cancer incidence $[111,112]$. Consequently, most ginsenoside 
TABle 1: Anticancer effects of some ginsenosides.

\begin{tabular}{|c|c|c|c|}
\hline Ginsenoside & Function & Cancer & Reference \\
\hline $\mathrm{Rd}$ & $\begin{array}{c}\downarrow \text { proliferation, migration, invasion, metastasis, angiogenesis, colony formation } \\
\uparrow \text { apoptosis, cell cycle arrest, sensitivity to cisplatin }\end{array}$ & $\begin{array}{l}\text { Breast } \\
\text { Gastric } \\
\text { Lung }\end{array}$ & $\begin{array}{l}{[56,57]} \\
{[109]} \\
{[130]}\end{array}$ \\
\hline CK & $\begin{array}{l}\downarrow \text { cell viability, tumor growth, invasion, migration, colony formation, metastasis, self-renewal } \\
\quad \text { capacity, self-renewal } \\
\qquad \begin{array}{c}\text { cell cycle arrest, apoptosis, autophagy }\end{array}\end{array}$ & $\begin{array}{l}\text { Breast } \\
\text { Brain } \\
\text { Liver } \\
\text { Lung }\end{array}$ & $\begin{array}{c}{[58,60]} \\
{[79]} \\
{[93,94]} \\
{[114,135,136]}\end{array}$ \\
\hline $\operatorname{Rg} 1$ & $\begin{array}{l}\downarrow \text { tumor growth, } \\
\uparrow \text { hepatoprotective }\end{array}$ & Liver & {$[91,92]$} \\
\hline $\operatorname{Rg} 2$ & $\uparrow$ autophagy & Breast & {$[64]$} \\
\hline Rg3 & $\begin{array}{l}\downarrow \text { cell viability, self-renewal capacity, proliferation, spheroid formation ability, angiogenesis, } \\
\text { metastasis, migration, invasion, EMT } \\
\qquad \begin{array}{l}\uparrow \text { apoptosis, autophagy, cell cycle arrest } \\
\uparrow \text { sensitivity to sorafenib, osimertinib, oxaliplatin, cisplatin, temozolomide, icotinib, gefitinib }\end{array}\end{array}$ & $\begin{array}{l}\text { Breast } \\
\text { Brain } \\
\text { Liver } \\
\text { Gastric } \\
\text { Lung }\end{array}$ & $\begin{array}{c}29,53,54] \\
{[32,73-75]} \\
{[83,84,95,96]} \\
{[104,105]} \\
{[115-117,123-128]}\end{array}$ \\
\hline $\operatorname{Rg} 5$ & $\begin{array}{l}\downarrow \text { proliferation, tumor growth } \\
\uparrow \text { cell cycle arrest, apoptosis, }\end{array}$ & $\begin{array}{l}\text { Breast } \\
\text { Gastric }\end{array}$ & $\begin{array}{c}{[59,62]} \\
{[108]}\end{array}$ \\
\hline $\operatorname{Rg} 18$ & $\begin{array}{c}\downarrow \text { proliferation } \\
\uparrow \text { cell cycle arrest } \\
\end{array}$ & Lung & {$[119]$} \\
\hline Rh1 & $\downarrow$ viability & Lung & [134] \\
\hline $\mathrm{Rh} 2$ & $\begin{array}{l}\downarrow \text { tumor growth, proliferation, invasion, angiogenesis, colony formation, migration, } \\
\qquad \begin{array}{l}\text { metastasis } \\
\uparrow \text { apoptosis, autophagy, cell cycle arrest }\end{array}\end{array}$ & $\begin{array}{l}\text { Breast } \\
\text { Brain } \\
\text { Liver } \\
\text { Gastric } \\
\text { Lung }\end{array}$ & $\begin{array}{c}{[66]} \\
{[72,78]} \\
{[86-90,97]} \\
{[109]} \\
{[120-122]} \\
\end{array}$ \\
\hline $\mathrm{Rk} 1$ & $\begin{array}{l}\downarrow \text { tumor growth, proliferation, colony formation, } \\
\uparrow \text { apoptosis, cell cycle arrest }\end{array}$ & $\begin{array}{c}\text { Breast } \\
\text { Lung }\end{array}$ & $\begin{array}{c}{[61]} \\
{[131]} \\
\end{array}$ \\
\hline Rk3 & $\begin{array}{l}\downarrow \text { viability, proliferation and colony formation, angiogenesis } \\
\qquad \uparrow \text { cell cycle arrest, apoptosis }\end{array}$ & Lung & {$[118]$} \\
\hline
\end{tabular}

studies on lung cancer have been focused on NSCLC. A recent study reported that $\mathrm{C}_{3} \mathrm{C}_{12} \mathrm{PPD}$, a newly discovered ginsenoside, inhibited cell growth, proliferation, migration, and tube formation of NSCLC in vivo and in vitro by inhibiting several signaling pathways, such as Raf/MEK/ERK, AKT/ mTOR, and AKT/GSK-3 $\beta / \beta$-catenin [113]. Furthermore, CK suppressed cell viability by downregulating HIF- $1 \alpha$ mediated glucose metabolism and increased autophagy-mediated apoptosis via AMPK-mTOR and JNK signaling pathways in NSCLC [114]. Rg3 inhibited epithelial-mesenchymal transition (EMT) and tumor growth by suppressing FUT4-mediated EGFR inactivation and the PI3K/Akt signaling pathway, as well as by promoting vaccinia-related kinase (VRK)1 expression [115-117]. Rk3 abrogated NSCLC xenograft tumor growth by causing cell cycle arrest at the G1 phase and apoptosis [118]. Similarly, Rg18 mediated G1 phase cell cycle arrest in A549 human NSCLC cells [119]. Rh2 converted tumor-associated macrophages from the M2 to M1 subset to prevent migration of lung cancer cells and repressed migration in the hypoxic environment via upregulating miR-491 expression [120, 121]. Additionally, Rh2 restrained NSCLC cell proliferation by inducing ROS-mediated cell apoptosis [122].

Ginsenosides have been known to improve the efficiency of currently used treatments against lung cancer. Rg3 improved sensitivity and suppressed resistance to several drugs, such as icotinib, gefitinib, cisplatin, gemcitabine, and osimertinib [123-128]. Several studies observed that Rk1 and Rg3 restricted programmed death ligand 1 (PD-L1) expression, $\mathrm{Rg} 3$ improved the efficacy of the epidermal growth factor receptor-tyrosine kinase inhibitor (EGFR-TKI), and Rd downregulated the NRF2 pathway to decrease acquired chemoresistance [128-131]. Moreover, several researchers have demonstrated that the anticancer effect and delivery of ginsenosides, such as Rh1, Rh2, and CK, can be further improved by conjugating them to polyethylene glycol (PEG), liposomes, and D- $\alpha$-tocopherol polyethylene glycol 1000 succinate (TPGS) [132-136]. Overall, ginsenosides exhibit their anticancer and antimetastatic properties in lung cancer cell lines and mice models via modulating signaling pathways and can promote the efficiency of current drugs.

\section{Conclusion}

Many in vivo and in vitro studies demonstrated that ginsenosides inhibit the growth and spread of several cancers by altering various signaling pathways and gene expression (Table 1). Although there have been a few clinic trials, most recent anticancer studies of ginsenosides were performed in cancer cell lines and mice xenograft models, with PPD ginsenosides being the most studied. Specifically, the ginsenosides Rg3 and Rh2 were the main focus of many studies and have been shown to have strong anticancer effects. 
Ginsenosides display their anticancer and antimetastatic properties not only via restricting cancer cell proliferation, viability, invasion, and migration but also by promoting apoptosis, cell cycle arrest, and autophagy. Moreover, the synergistic effect of ginsenosides with existing cancer therapies has been confirmed. Acquired chemoresistance can be reversed or suppressed by ginsenosides, improving sensitivity to drugs in patients treated with chemotherapy. Taken together, ginsenosides have been proven to be effective anticancer agents through many studies; however, more clinical trials are needed to determine whether ginsenosides can be used as the main ingredients for new drugs or as supplements to existing cancer treatments.

\section{Data Availability}

No data were used in the study.

\section{Conflicts of Interest}

The authors declare that they have no conflicts of interest.

\section{Authors' Contributions}

Heeok Hong and Seong Gu Hwang contributed to the conception of this manuscript. Heeok Hong and Delgerzul Baatar organized and drafted the manuscript. Heeok Hong, Delgerzul Baatar, and Seong Gu Hwang reviewed and revised the manuscript.

\section{Acknowledgments}

This work was supported by Konkuk University.

\section{References}

[1] World Health Organization, WHO Report on Cancer: Setting Priorities, Investing Wisely and Providing Care for All, World Health Organization, Geneva, Switzerland, 2020.

[2] M. Sun, Y. Ye, L. Xiao, X. Duan, Y. Zhang, and H. Zhang, "Anticancer effects of ginsenoside Rg3 (review)," International Journal of Molecular Medicine, vol. 39, no. 3, pp. 507-518, 2017.

[3] L. Pan, T. Zhang, H. Sun, and G. Liu, "Ginsenoside Rg3 (Shenyi capsule) combined with chemotherapy for digestive system cancer in China: a meta-analysis and systematic review," Evidence-Based Complementary and Alternative Medicine, vol. 2019, Article ID 2417418, 19 pages, 2019.

[4] M. He, X. Huang, S. Guo, Y. Xie, A. H. Meijer, and M. Wang, "The difference between white and red ginseng: variations in ginsenosides and immunomodulation," Planta Medica, vol. 84, no. 12-13, pp. 845-854, 2018.

[5] H.-D. Yuan, J.-T. Kim, S.-H. Kim, and S.-H. Chung, "Ginseng and diabetes: the evidences from in vitro, animal and human studies," Journal of Ginseng Research, vol. 36, no. 1, pp. 27-39, 2012.

[6] S. I. Chung, M. Y. Kang, and S. C. Lee, "In vitro and in vivo antioxidant activity of aged ginseng (Panax ginseng)," Preventive Nutrition and Food Science, vol. 21, no. 1, pp. 24-30, 2016.

[7] J.-H. Kim, "Pharmacological and medical applications of Panax ginseng and ginsenosides: a review for use in cardiovascular diseases," Journal of Ginseng Research, vol. 42, no. 3, pp. 264-269, 2018.

[8] H.-M. Park, S.-J. Kim, J.-S. Kim, and H.-S. Kang, "Reactive oxygen species mediated ginsenoside Rg3- and Rh2-induced apoptosis in hepatoma cells through mitochondrial signaling pathways," Food and Chemical Toxicology, vol. 50, no. 8, pp. 2736-2741, 2012.

[9] E. J. Joo, J. Chun, Y. W. Ha, H. J. Ko, M.-Y. Xu, and Y. S. Kim, "Novel roles of ginsenoside $\mathrm{Rg} 3$ in apoptosis through downregulation of epidermal growth factor receptor," Chemico-Biological Interactions, vol. 233, pp. 25-34, 2015.

[10] X. Jin, D.-B. Che, Z.-H. Zhang, H.-M. Yan, Z.-Y. Jia, and $\mathrm{X}$.-B. Jia, "Ginseng consumption and risk of cancer: a metaanalysis," Journal of Ginseng Research, vol. 40, no. 3, pp. 269-277, 2016.

[11] T. Chen, B. Li, Y. Qiu, Z. Qiu, and P. Qu, "Functional mechanism of Ginsenosides on tumor growth and metastasis," Saudi Journal of Biological Sciences, vol. 25, no. 5, pp. 917-922, 2018.

[12] P. Mohanan, S. Subramaniyam, R. Mathiyalagan, and D.-C. Yang, "Molecular signaling of ginsenosides Rb1, Rg1, and Rg3 and their mode of actions," Journal of Ginseng Research, vol. 42, no. 2, pp. 123-132, 2018.

[13] T. K. Yun, "Brief introduction of Panax ginseng C.A. Meyer," Journal of Korean Medical Science, vol. 16, pp. S3-S5, 2001.

[14] I.-H. Baeg and S.-H. So, "The world ginseng market and the ginseng (Korea)," Journal of Ginseng Research, vol. 37, no. 1, pp. 1-7, 2013.

[15] H. Park, "The history of ginseng cultivation in the orient," Acta Horticulturae, vol. 620, no. 620, pp. 453-460, 2003.

[16] H.-J. Park, D.-H. Kim, S.-J. Park, J.-M. Kim, and J.-H. Ryu, "Ginseng in traditional herbal prescriptions," Journal of Ginseng Research, vol. 36, no. 3, pp. 225-241, 2012.

[17] S.-W. Kang and H.-Y. Min, "Ginseng, the "immunity boost": the effects of Panax ginseng on immune system," Journal of Ginseng Research, vol. 36, no. 4, pp. 354-368, 2012.

[18] M. Yun and Y.-S. Yi, "Regulatory roles of ginseng on inflammatory caspases, executioners of inflammasome activation," Journal of Ginseng Research, vol. 44, no. 3, pp. 373-385, 2020.

[19] N. H. Tung, T. Uto, O. Morinaga et al., "Pharmacological effects of ginseng on liver functions and diseases: a minireview," Evidence-Based Complementary and Alternative Medicine, vol. 2012, Article ID 173297, 7 pages, 2012.

[20] Z. Li and G. E. Ji, "Ginseng and obesity," Journal of Ginseng Research, vol. 42, no. 1, pp. 1-8, 2018.

[21] H. Iqbal and D.-k. Rhee, "Ginseng alleviates microbial infections of the respiratory tract: a review," Journal of Ginseng Research, vol. 44, no. 2, pp. 194-204, 2020.

[22] K.-C. Park, H. Jin, R. Zheng et al., "Cognition enhancing effect of Panax ginseng in Korean volunteers with mild cognitive impairment: a randomized, double-blind, placebocontrolled clinical trial," Translational and Clinical Pharmacology, vol. 27, no. 3, pp. 92-97, 2019.

[23] J.-I. Lee, K. S. Park, and I.-H. Cho, "Panax ginseng: a candidate herbal medicine for autoimmune disease," Journal of Ginseng Research, vol. 43, no. 3, pp. 342-348, 2019.

[24] H.-J. Kim, S.-W. Jung, S.-Y. Kim et al., "Panax ginseng as an adjuvant treatment for Alzheimer's disease," Journal of Ginseng Research, vol. 42, no. 4, pp. 401-411, 2018.

[25] S. Lee and D.-K. Rhee, "Effects of ginseng on stress-related depression, anxiety, and the hypothalamic-pituitary-adrenal axis," Journal of Ginseng Research, vol. 41, no. 4, pp. 589-594, 2017. 
[26] J. Kim, S.-Y. Han, and H. Min, "Ginseng for an eye: effects of ginseng on ocular diseases," Journal of Ginseng Research, vol. 44, no. 1, pp. 1-7, 2020.

[27] B. C. He, J. L. Gao, X. Luo et al., "Ginsenoside Rg3 inhibits colorectal tumor growth through the down-regulation of Wnt/ss-catenin signaling," International Journal of Oncology, vol. 38, pp. 437-445, 2011.

[28] E. J. Kim, K. A. Kwon, Y. E. Lee, J. H. Kim, S.-H. Kim, and J. H. Kim, "Korean Red Ginseng extract reduces hypoxiainduced epithelial-mesenchymal transition by repressing NF- $\kappa$ B and ERK1/2 pathways in colon cancer," Journal of Ginseng Research, vol. 42, no. 3, pp. 288-297, 2018.

[29] J. Oh, H.-J. Yoon, J.-H. Jang, D.-H. Kim, and Y.-J. Surh, “The standardized Korean Red Ginseng extract and its ingredient ginsenoside $\operatorname{Rg} 3$ inhibit manifestation of breast cancer stem cell-like properties through modulation of self-renewal signaling," Journal of Ginseng Research, vol. 43, no. 3, pp. 421-430, 2019.

[30] J. W. Kim, S. W. Han, J. Y. Cho et al., "Korean red ginseng for cancer-related fatigue in colorectal cancer patients with chemotherapy: a randomised phase III trial," European Journal of Cancer, vol. 130, pp. 51-62, 2020.

[31] Y. H. Kim, Y. Lim, J. Y. Cho et al., "Korean red ginseng to improve cancer-related fatigue in colorectal cancer patients with FOLFOX chemotherapy: a randomized, double-blind, placebo-controlled, parallel, multicenter trial, NCT02039635," Journal of Clinical Oncology, vol. 35, no. 15, Article ID 10008, 2017.

[32] S. W. Ham, J.-K. Kim, H.-Y. Jeon et al., "Korean red ginseng extract inhibits glioblastoma propagation by blocking the Wnt signaling pathway," Journal of Ethnopharmacology, vol. 236, pp. 393-400, 2019.

[33] I.-S. Lee, K. S. Kang, and S.-Y. Kim, "Panax ginseng pharmacopuncture: current status of the research and future challenges," Biomolecules, vol. 10, no. 1, p. 33, 2019.

[34] S. H. Hyun, S. W. Kim, H. W. Seo et al., "Physiological and pharmacological features of the non-saponin components in Korean red ginseng," Journal of Ginseng Research, vol. 44, no. 4, pp. 527-537, 2020.

[35] B. Zhao, C. Lv, and J. Lu, "Natural occurring polysaccharides from Panax ginseng C. A. Meyer: a review of isolation, structures, and bioactivities," International Journal of Biological Macromolecules, vol. 133, pp. 324-336, 2019.

[36] T. B. Ng, J. Wong, R. Chi et al., "Biologically active proteins in ginseng," International Journal of Biomedical and Pharmaceutical Science, vol. 6, pp. 25-32, 2012.

[37] S.-H. Kim, S.-Y. Kim, and H.-K. Choi, "Lipids in ginseng (Panax ginseng) and their analysis," Natural Product Sciences, vol. 24, no. 1, pp. 1-12, 2018.

[38] Y. Yang, Z. Ju, Y. Yang, Y. Zhang, L. Yang, and Z. Wang, "Phytochemical analysis of Panax species: a review," Journal of Ginseng Research, vol. 45, no. 1, p. 1, 2021.

[39] B.-K. Shin, S. W. Kwon, and J. H. Park, "Chemical diversity of ginseng saponins from Panax ginseng," Journal of Ginseng Research, vol. 39, no. 4, pp. 287-298, 2015.

[40] Z. A. Ratan, M. F. Haidere, Y. H. Hong et al., "Pharmacological potential of ginseng and its major component ginsenosides," Journal of Ginseng Research, 2020.

[41] B. Delgerzul, M. Z. Siddiqi, W. T. Im et al., "Anti-inflammatory effect of ginsenoside Rh2-Mix on lipopolysaccharide-stimulated RAW 264.7 murine macrophage cells," Journal of Medicinal Food, vol. 21, pp. 951-960, 2018.

[42] X. Yang, L. Ma, H. Zhao et al., "Differentiation and identification of ginsenoside structural isomers by two-dimensional mass spectrometry combined with statistical analysis," Journal of Ginseng Research, vol. 43, pp. 368-376, 2019.

[43] Y. Han, J. Zhao, J. You et al., "Factors influencing cultivated ginseng (Panax ginseng C. A. Meyer) bioactive compounds," PLoS One, vol. 14, Article ID e0223763, 2019.

[44] M.-M. Zheng, F.-X. Xu, Y.-J. Li et al., "Study on transformation of ginsenosides in different methods," Biomed Research International, vol. 2017, Article ID 8601027, 10 pages, 2017.

[45] D. G. Lee, J. S. Lee, K.-T. Kim, H. Y. Kim, and S. Lee, "Analysis of major ginsenosides in various ginseng samples," Journal of Applied Biological Chemistry, vol. 62, no. 1, pp. 87-91, 2019.

[46] H. Suh, S. M. Seo, D. S. Lee, and S. Y. Woo, "Ginsenosides contents of forest cultivated ginseng (Panax ginseng) in Korea," Forest Science and Technology, vol. 6, no. 2, pp. 118-121, 2010.

[47] X. G. Li, Y. Z. Yan, X. J. Jin et al., "Ginsenoside content in the leaves and roots of Panax ginseng at different ages," Life Science Journal, vol. 9, pp. 679-683, 2012.

[48] Z. Liu, C.-Z. Wang, X.-Y. Zhu et al., "Dynamic changes in neutral and acidic ginsenosides with different cultivation ages and harvest seasons: identification of chemical characteristics for Panax ginseng quality control," Molecules, vol. 22, no. 5, p. 734, 2017.

[49] B. W. Yang, J. B. Lee, J. M. Lee et al., "The comparison of seasonal ginsenoside composition contents in Korean wild simulated ginseng (Panax ginseng) which were cultivated in different areas and various ages," Natural Product Sciences, vol. 25, no. 1, p. 1, 2019.

[50] S.-E. Park, C.-S. Na, S.-A. Yoo, S.-H. Seo, and H.-S. Son, "Biotransformation of major ginsenosides in ginsenoside model culture by lactic acid bacteria," Journal of Ginseng Research, vol. 41, no. 1, pp. 36-42, 2017.

[51] N. Harbeck, F. Penault-Llorca, J. Cortes et al., "Breast cancer," Nature Reviews Disease Primers, vol. 5, no. 1, Article ID 66, 2019.

[52] Z. Momenimovahed and H. Salehiniya, "Epidemiological characteristics of and risk factors for breast cancer in the world," Breast Cancer: Targets and Therapy, vol. 11, pp. 151-164, 2019.

[53] M. Zou, J. Wang, J. Gao, H. Han, and Y. Fang, "Phosphoproteomic analysis of the antitumor effects of ginsenoside Rg3 in human breast cancer cells," Oncology Letters, vol. 15, no. 3, pp. 2889-2898, 2018.

[54] J. Ham, S. Lee, H. Lee, D. Jeong, S. Park, and S. J. Kim, "Genome-wide methylation analysis identifies NOX4 and KDM5A as key regulators in inhibiting breast cancer cell proliferation by ginsenoside Rg3," The American Journal of Chinese Medicine, vol. 46, no. 6, pp. 1333-1355, 2018.

[55] H. Lee, S. Lee, D. Jeong, and S. J. Kim, "Ginsenoside Rh2 epigenetically regulates cell-mediated immune pathway to inhibit proliferation of MCF-7 breast cancer cells," Journal of Ginseng Research, vol. 42, no. 4, pp. 455-462, 2018.

[56] P. Wang, X. Du, M. Xiong et al., "Ginsenoside Rd attenuates breast cancer metastasis implicating derepressing microrna18A-regulated smad2 expression," Scientific Reports, vol. 6, no. 1, 2016.

[57] E. Zhang, H. Shi, L. Yang, X. Wu, and Z. Wang, "Ginsenoside $\mathrm{Rd}$ regulates the Akt/mTOR/p70S6K signaling cascade and suppresses angiogenesis and breast tumor growth," Oncology Reports, vol. 38, no. 1, pp. 359-367, 2017. 
[58] E. Choi, E. Kim, J. H. Kim et al., "AKT1-targeted proapoptotic activity of compound $\mathrm{K}$ in human breast cancer cells," Journal of Ginseng Research, vol. 43, no. 4, pp. 692-698, 2019.

[59] Y. Liu and D. Fan, "Ginsenoside Rg5 induces apoptosis and autophagy via the inhibition of the PI3K/Akt pathway against breast cancer in a mouse model," Food \& Function, vol. 9, no. 11, pp. 5513-5527, 2018.

[60] S. J. Lee, J. S. Lee, E. Lee, T.-G. Lim, and S. Byun, "The ginsenoside metabolite compound $\mathrm{K}$ inhibits hormone-independent breast cancer through downregulation of cyclin D1," Journal of Functional Foods, vol. 46, pp. 159-166, 2018.

[61] Y. Hong and D. Fan, "Ginsenoside Rk1 induces cell cycle arrest and apoptosis in MDA-MB-231 triple negative breast cancer cells," Toxicology, vol. 418, pp. 22-31, 2019.

[62] C. Porta, C. Paglino, and A. Mosca, "Targeting PI3K/Akt/ mTOR signaling in cancer," Frontiers in Oncology, vol. 4, p. 64, 2014.

[63] S.-J. Kim and A. K. Kim, "Anti-breast cancer activity of fine black ginseng (Panax ginseng Meyer) and ginsenoside Rg5," Journal of Ginseng Research, vol. 39, no. 2, pp. 125-134, 2015.

[64] Y. Chung, S. Jeong, H. S. Choi, S. Ro, J. S. Lee, and J. K. Park, "Upregulation of autophagy by ginsenoside Rg2 in MCF-7 cells," Animal Cells and Systems, vol. 22, no. 6, pp. 382-389, 2018.

[65] K.-K. Li, X.-M. Yan, Z.-N. Li, Q. Yan, and X.-J. Gong, "Synthesis and antitumor activity of three novel ginsenoside M1 derivatives with 3 '-ester modifications," Bioorganic Chemistry, vol. 90, Article ID 103061, 2019.

[66] G. Ren, C. Wu, C. Teng, and Y. Yao, "Synergistic effect of combined protopanaxatiol and ginsenoside Rh2 on antiproliferative activity in MDA-MB-231 human breast cancer cells in vitro," Food and Agricultural Immunology, vol. 29, no. 1, pp. 953-963, 2018.

[67] P. Nakhjavani, T. Palethorpe, P. Tomita et al., "Stereoselective anti-cancer activities of ginsenoside Rg3 on triple negative breast cancer cell models," Pharmaceuticals, vol. 12, no. 3, p. 117, 2019.

[68] P. J. C. Lonkhuizen, K. M. Klaver, J. S. Wefel, M. M. Sitskoorn, S. B. Schagen, and K. Gehring, "Interventions for cognitive problems in adults with brain cancer: a narrative review," European Journal of Cancer Care, vol. 28, no. 3, Article ID e13088, 2019.

[69] G. S. Tandel, M. Biswas, O. G. Kakde et al., "A review on a deep learning perspective in brain cancer classification," Cancers, vol. 11, no. 1, p. 111, 2019.

[70] K. Aldape, K. M. Brindle, L. Chesler et al., "Challenges to curing primary brain tumours," Nature Reviews Clinical Oncology, vol. 16, no. 8, pp. 509-520, 2019.

[71] C. W. Brennan, R. G. W. Verhaak, A. McKenna et al., "The somatic genomic landscape of glioblastoma," Cell, vol. 155, no. 2, pp. 462-477, 2013.

[72] Y. Chen, H. Shang, S. Zhang, and X. Zhang, "Ginsenoside Rh2 inhibits proliferation and migration of medulloblastoma Daoy by down-regulation of microRNA-31," Journal of Cellular Biochemistry, vol. 119, no. 8, pp. 6527-6534, 2018.

[73] C. Sun, Y. Yu, L. Wang et al., "Additive antiangiogenesis effect of ginsenoside $\mathrm{Rg} 3$ with low-dose metronomic temozolomide on rat glioma cells both in vivo and in vitro," Journal of Experimental \& Clinical Cancer Research, vol. 35, no. 1, p. 32, 2016.

[74] Z. Chen, X. Wei, L. Shen, H. Zhu, and X. Zheng, "20(S)ginsenoside- $\operatorname{Rg} 3$ reverses temozolomide resistance and restrains epithelial-mesenchymal transition progression in glioblastoma," Cancer Science, vol. 110, no. 1, pp. 389-400, 2018.

[75] J. Hou, S. Kim, C. Sung, and C. Choi, "Ginsenoside Rg3 prevents oxidative stress-induced astrocytic senescence and ameliorates senescence paracrine effects on glioblastoma," Molecules, vol. 22, no. 9, p. 1516, 2017.

[76] J. Hou, C. Cui, S. Kim, C. Sung, and C. Choi, "Ginsenoside F1 suppresses astrocytic senescence-associated secretory phenotype," Chemico-Biological Interactions, vol. 283, pp. 75-83, 2018.

[77] X. Kang, W. Hong, K. Xie et al., "Ginsenoside Rb1 pretreatment reverses hippocampal changes in BDNF/Trkb Mrna and protein in rats subjected to acute immobilization stress," Drug Design, Development and Therapy, vol. 13, pp. 2127-2134, 2019.

[78] N. Guan, X. Huo, Z. Zhang, S. Zhang, J. Luo, and W. Guo, "Ginsenoside Rh2 inhibits metastasis of glioblastoma multiforme through Akt-regulated MMP13," Tumor Biology, vol. 36, no. 9, pp. 6789-6795, 2015.

[79] S. Lee, M. C. Kwon, J.-P. Jang, J. K. Sohng, and H. J. Jung, "The ginsenoside metabolite compound $\mathrm{K}$ inhibits growth, migration and stemness of glioblastoma cells," International Journal of Oncology, vol. 51, no. 2, pp. 414-424, 2017.

[80] J. Balogh, D. Victor, E. H. Asham et al., "Hepatocellular carcinoma: a review," Journal of Hepatocellular Carcinoma, vol. 3, pp. 41-53, 2016.

[81] J. D. Yang, P. Hainaut, G. J. Gores, A. Amadou, A. Plymoth, and L. R. Roberts, "A global view of hepatocellular carcinoma: trends, risk, prevention and management," Nature Reviews Gastroenterology \& Hepatology, vol. 16, no. 10, pp. 589-604, 2019.

[82] Z. Lu, H. Xu, X. Yu et al., "20(S)-protopanaxadiol induces apoptosis in human hepatoblastoma HepG2 cells by downregulating the protein kinase B signaling pathway," Experimental and Therapeutic Medicine, vol. 15, pp. 12771284, 2018.

[83] X. Li, J. Tsauo, C. Geng, H. Zhao, X. Lei, and X. Li, "Ginsenoside Rg3 decreases NHE1 expression via inhibiting EGF-EGFRERK1/2-HIF-1 $\alpha$ pathway in hepatocellular carcinoma: a novel antitumor mechanism," The American Journal of Chinese Medicine, vol. 46, no. 8, pp. 1915-1931, 2018.

[84] M. Y. Sun, Y. N. Song, M. Zhang, C. Y. Zhang, L. J. Zhang, and H. Zhang, "Ginsenoside Rg3 inhibits the migration and invasion of liver cancer cells by increasing the protein expression of ARHGAP9," Oncology Letters, vol. 17, no. 1, pp. 965-973, 2019.

[85] H. Zhang, Q. F. Tang, M. Y. Sun et al., "ARHGAP9 suppresses the migration and invasion of hepatocellular carcinoma cells through up-regulating FOXJ2/E-cadherin," Cell Death \& Disease, vol. 9, p. 916, 2018.

[86] W. Chen and Y. Qiu, "Ginsenoside Rh2 targets EGFR by upregulation of Mir-491 to enhance anti-tumor activity in hepatitis B virus-related hepatocellular carcinoma," Cell Biochemistry and Biophysics, vol. 72, no. 2, pp. 325-331, 2015.

[87] Z. Yang, T. Zhao, H. Liu, and L. Zhang, "Ginsenoside Rh2 inhibits hepatocellular carcinoma through $\beta$-catenin and autophagy," Scientific Reports, vol. 6, no. 1, Article ID 1938, 2016.

[88] W. Chen, S. Chu, H. Li, and Y. Qiu, "MicroRNA-146a-5p enhances ginsenoside $\mathrm{Rh} 2$-induced anti-proliferation and the apoptosis of the human liver cancer cell line HepG2," Oncology Letters, vol. 16, pp. 5367-5374, 2018

[89] Q. Lv, N. Rong, L.-J. Liu et al., "Antitumoral activity of (20R)- and (20S)-ginsenoside Rh2 on transplanted 
hepatocellular carcinoma in mice," Planta Medica, vol. 82, no. 8, pp. 705-711, 2016.

[90] Y.-S. Wang, Y. Lin, H. Li, Y. Li, Z. Song, and Y.-H. Jin, "The identification of molecular target of (20S) ginsenoside Rh2 for its anti-cancer activity," Scientific Reports, vol. 7, no. 1, 2017.

[91] M. H. Xiao, J. Y. Xia, Z. L. Wang et al., "Ginsenoside Rg1 attenuates liver injury induced by D-galactose in mice," Experimental and Therapeutic Medicine, vol. 16, pp. 41004106, 2018

[92] N. Zhen, L. Jin, J. Ma et al., "Ginsenoside Rg1 impairs homologous recombination repair by targeting CtBPinteracting protein and sensitizes hepatoblastoma cells to DNA damage," Anti-Cancer Drugs, vol. 29, pp. 1-766, 2018.

[93] X. Zhang, S. Zhang, Q. Sun, W. Jiao, Y. Yan, and X. Zhang, "Compound $\mathrm{K}$ induces endoplasmic reticulum stress and apoptosis in human liver cancer cells by regulating STAT3," Molecules, vol. 23, no. 6, p. 1482, 2018.

[94] J. Hou, J. Xue, X. Zhao et al., "Octyl ester of ginsenoside compound $\mathrm{K}$ as novel anti-hepatoma compound: synthesis and evaluation on murine $\mathrm{H} 22$ cells in vitro and in vivo," Chemical Biology \& Drug Design, vol. 91, no. 4, pp. 951-956, 2017.

[95] K. Shan, Y. Wang, H. Hua, S. Qin, A. Yang, and J. Shao, "Ginsenoside Rg3 combined with oxaliplatin inhibits the proliferation and promotes apoptosis of hepatocellular carcinoma cells via downregulating PCNA and cyclin D1," Biological and Pharmaceutical Bulletin, vol. 42, no. 6, pp. 900-905, 2019.

[96] M. Lu, Z. Fei, and G. Zhang, "Synergistic anticancer activity of 20(S)-ginsenoside Rg3 and sorafenib in hepatocellular carcinoma by modulating PTEN/Akt signaling pathway," Biomedicine \& Pharmacotherapy, vol. 97, pp. 1282-1288, 2018.

[97] B. Wang, F. Wang, A. Ding, H. Zhao, and X. Bu, "Regorafenib and ginsenoside combination therapy: inhibition of HepG2 cell growth through modulating survivin and caspase-3 gene expression," Clinical and Translational Oncology, vol. 22, no. 9, pp. 1491-1498, 2020.

[98] B. Zhou, Z. Yan, R. Liu et al., "Prospective study of transcatheter arterial chemoembolization (TACE) with ginsenoside Rg3 versus TACE alone for the treatment of patients with advanced hepatocellular carcinoma," Radiology, vol. 280, no. 2, pp. 630-639, 2016.

[99] R. Sitarz, M. Skierucha, J. Mielko, J. Offerhaus, R. Maciejewski, and W. Polkowski, "Gastric cancer: epidemiology, prevention, classification, and treatment," Cancer Management and Research, vol. 10, pp. 239-248, 2018.

[100] D. Ye, G. Xu, W. Ma et al., "Significant function and research progress of biomarkers in gastric cancer (review)," Oncology Letters, vol. 19, pp. 17-29, 2019.

[101] C. Zhao, G. Su, X. Wang, X. Zhang, S. Guo, and Y. Zhao, "Antitumor activity of ginseng sapogenins, 25-OH-PPD and 25-OCH3-PPD, on gastric cancer cells," Biotechnology Letters, vol. 38, no. 1, pp. 43-50, 2015.

[102] X. D. Wang, Y. Y. Sun, F. Z. Qu, G. Y. Su, and Y. Q. Zhao, “4$\mathrm{XL}-\mathrm{PPD}$, a novel ginsenoside derivative, as potential therapeutic agents for gastric cancer shows anti-cancer activity via inducing cell apoptosis medicated generation of reactive oxygen species and inhibiting migratory and invasive," Biomedicine \& Pharmacotherapy, vol. 118, Article ID 108589, 2019.

[103] D. Wang, T. Li, Y. Li et al., "2-Pyrazine-PPD, a novel dammarane derivative, showed anticancer activity by reactive oxygen species-mediate apoptosis and endoplasmic reticulum stress in gastric cancer cells," European Journal of Pharmacology, vol. 881, Article ID 173211, 2020.

[104] X. Dai, D. Liu, M. Liu et al., "Anti-metastatic efficacy of traditional chinese medicine (TCM) ginsenoside conjugated to a VEFGR-3 antibody on human gastric cancer in an orthotopic mouse model," Anticancer Research, vol. 37, no. 3, pp. 979-986, 2017.

[105] B. Li and G. Qu, "Inhibition of the hypoxia-induced factor$1 \alpha$ and vascular endothelial growth factor expression through ginsenoside Rg3 in human gastric cancer cells," Journal of Cancer Research and Therapeutics, vol. 15, pp. 1642-1646, 2019.

[106] F. Aziz, X. Wang, J. Liu, and Q. Yan, "Ginsenoside Rg3 induces FUT4-mediated apoptosis in $H$. pylori CagA-treated gastric cancer cells by regulating SP1 and HSF1 expressions," Toxicology in Vitro, vol. 31, pp. 158-166, 2016.

[107] W. Liu, H.-f. Pan, L.-j. Yang et al., "Panax ginseng C.A. Meyer (Rg3) ameliorates gastric precancerous lesions in Atp4a-/- mice via inhibition of glycolysis through PI3K/ AKT/miRNA-21 pathway," Evidence-Based Complementary and Alternative Medicine, vol. 2020, Article ID 2672648, 8 pages, 2020

[108] Y. Liu and D. Fan, "Ginsenoside Rg5 induces G2/M phase arrest, apoptosis and autophagy via regulating ROS-mediated MAPK pathways against human gastric cancer," Biochemical Pharmacology, vol. 168, pp. 285-304, 2019.

[109] J. Qian, J. Li, J.-G. Jia et al., "Ginsenoside-Rh2 inhibits proliferation and induces apoptosis of human gastric cancer SGC-7901 side population cells," Asian Pacific Journal of Cancer Prevention, vol. 17, no. 4, pp. 1817-1821, 2016.

[110] Y. Z. Tian, Y. P. Liu, S. C. Tian, S. Y Ge, Y. J Wu, and B. L Zhang, "Antitumor activity of ginsenoside Rd in gastric cancer via up-regulation of caspase-3 and caspase-9," Die Pharmazie, vol. 75, no. 4, pp. 147-150, 2020.

[111] L. A. Hassan, O. Hassan, Y. W. Yang et al., "Lung cancer: biology and treatment options," Biochimica et Biophysica Acta, vol. 1856, pp. 189-210, 2015.

[112] K. Inamura, "Lung cancer: understanding its molecular pathology and the 2015 WHO classification," Frontiers in Oncology, vol. 7, p. 193, 2017.

[113] L.-L. Huang, M. Tang, Q.-Q. Du et al., "The effects and mechanisms of a biosynthetic ginsenoside 3B,12 $\beta-\mathrm{Di}-\mathrm{O}$ Glc-PPD on non-small cell lung cancer," Oncotargets and Therapy, vol. 12, pp. 7375-7385, 2019.

[114] C. Li, Y. Dong, L. Wang et al., "Ginsenoside metabolite compound $\mathrm{K}$ induces apoptosis and autophagy in non-small cell lung cancer cells via AMPK-mTOR and JNK pathways," Biochemistry and Cell Biology, vol. 97, pp. 406-414, 2019.

[115] L. Tian, D. Shen, X. Li et al., "Ginsenoside Rg3 inhibits epithelial-mesenchymal transition (EMT) and invasion of lung cancer by down-regulating FUT4," Oncotarget, vol. 7, pp. 1619-1632, 2015.

[116] Q. Xie, H. Wen, Q. Zhang et al., "Inhibiting PI3K-Akt signaling pathway is involved in antitumor effects of ginsenoside Rg3 in lung cancer cell," Biomedicine \& Pharmacotherapy, vol. 85, pp. 16-21, 2017.

[117] T. Liu, L. Zuo, D. Guo et al., "Ginsenoside Rg3 regulates DNA damage in non-small cell lung cancer cells by activating VRK1/P53BP1 pathway," Biomedicine \& Pharmacotherapy, vol. 120, p. 109483, 2019.

[118] Z. Duan, J. Deng, Y. Dong et al., "Anticancer effects of ginsenoside $\mathrm{Rk} 3$ on non-small cell lung cancer cells: in vitro and in vivo," Food \& Function, vol. 8, pp. 3723-3736, 2017. 
[119] D. G. Leem, J. S. Shin, K. T. Kim et al., "Dammarane-type triterpene ginsenoside-Rg18 inhibits human non-small cell lung cancer A549 cell proliferation via G1 phase arrest," Oncology Letters, vol. 15, pp. 6043-6049, 2018.

[120] H. Li, N. Huang, W. Zhu et al., "Modulation the crosstalk between tumor-associated macrophages and non-small cell lung cancer to inhibit tumor migration and invasion by ginsenoside Rh2," BMC Cancer, vol. 18, p. 579, 2018.

[121] Y. Chen, Y. Zhang, W. Song et al., "Ginsenoside Rh2 inhibits migration of lung cancer cells under hypoxia via mir-491," Anti-Cancer Agents in Medicinal Chemistry, vol. 19, pp. 1633-1641, 2019.

[122] G. Ge, Y. Yan, and H. Cai, "Ginsenoside Rh2 inhibited proliferation by inducing ROS mediated ER stress dependent apoptosis in lung cancer cells," Biological \& Pharmaceutical Bulletin, vol. 40, pp. 2117-2124, 2017.

[123] Y. Dai, W. Wang, Q. Sun et al., "Ginsenoside Rg3 promotes the antitumor activity of gefitinib in lung cancer cell lines," Experimental and Therapeutic Medicine, vol. 17, pp. 953-959, 2018.

[124] J. Wang, L. Tian, M. N. Khan et al., "Ginsenoside Rg3 sensitizes hypoxic lung cancer cells to cisplatin via blocking of NF- $\kappa \mathrm{B}$ mediated epithelial-mesenchymal transition and stemness," Cancer Letters, vol. 415, pp. 73-85, 2018.

[125] B. Ahmmed, S. Kampo, M. Khan et al., "Rg3 inhibits gemcitabine-induced lung cancer cell invasiveness through ROS-dependent, NF- $\kappa \mathrm{B}$ - and HIF- $1 \alpha$-mediated downregulation of PTX3," Journal of Cellular Physiology, vol. 234, pp. 10680-10697, 2019.

[126] X. J. Wang, R. J. Zhou, N. Zhang et al., "20(S)-ginsenoside Rg3 sensitizes human non-small cell lung cancer cells to icotinib through inhibition of autophagy," European Journal of Pharmacology, vol. 850, pp. 141-149, 2019.

[127] Q. Tan, S. Lin, Y. Zeng et al., "Ginsenoside Rg3 attenuates the osimertinib resistance by reducing the stemness of non-small cell lung cancer cells," Environmental Toxicology, vol. 35, pp. 643-651, 2020.

[128] Z. Jiang, Y. Yang, Y. Yang et al., "Ginsenoside Rg3 attenuates cisplatin resistance in lung cancer by downregulating PD-L1 and resuming immune," Biomedicine \& Pharmacotherapy, vol. 96, pp. 378-383, 2017.

[129] Y. Li, Y. Wang, K. Niu et al., "Clinical benefit from EGFRTKI plus ginsenoside Rg3 in patients with advanced nonsmall cell lung cancer harboring EGFR active mutation," Oncotarget, vol. 7, pp. 70535-70545, 2016.

[130] S. Chian, Y. Zhao, M. Xu et al., "Ginsenoside Rd reverses cisplatin resistance in non-small-cell lung cancer A549 cells by downregulating the nuclear factor erythroid 2-related factor 2 pathway," Anti-Cancer Drugs, vol. 30, pp. 838-845, 2019.

[131] M. Hu, J. Yang, L. Qu et al., "Ginsenoside Rk1 induces apoptosis and downregulates the expression of PD-L1 by targeting the NF- $\kappa \mathrm{B}$ pathway in lung adenocarcinoma," Food \& Function, vol. 11, pp. 456-471, 2020.

[132] X. Jin, J. Zhou, Z. Zhang et al., "The combined administration of parthenolide and ginsenoside CK in long circulation liposomes with targeted Tlyp-1 ligand induce mitochondria-mediated lung cancer apoptosis," Artificial Cells, Nanomedicine, and Biotechnology, vol. 46, pp. S931S942, 2018.

[133] P. Li, X. Y. Zhou, D. Qu et al., "Preliminary study on fabrication, characterization and synergistic anti-lung cancer effects of self-assembled micelles of covalently conjugated celastrol-polyethylene glycol-ginsenoside Rh2," Drug Delivery, vol. 24, pp. 834-845, 2017.

[134] R. Mathiyalagan, C. Wang, Y. J. Kim et al., "Preparation of polyethylene glycol-ginsenoside $\mathrm{Rh} 1$ and $\mathrm{Rh} 2$ conjugates and their efficacy against lung cancer and inflammation," Molecules, vol. 24, p. 4367, 2019.

[135] L. Yang, J. Xin, Z. Zhang et al., "TPGS-modified liposomes for the delivery of ginsenoside compound $\mathrm{K}$ against nonsmall cell lung cancer: formulation design and its evaluation in vitro and in vivo," Journal of Pharmacy and Pharmacology, vol. 68, pp. 1109-1118, 2016.

[136] L. Yang, Z. Zhang, J. Hou et al., "Targeted delivery of ginsenoside compound $\mathrm{K}$ using TPGS/PEG-PCL mixed micelles for effective treatment of lung cancer," International Journal of Nanomedicine, vol. 12, pp. 7653-7667, 2017. 